\title{
Editorial
}

\section{Experiências e contribuições no campo da infância e adolescência}

\author{
Elisabete Ferreira Mângia ${ }^{1}$, Maria Inês Britto Brunello ${ }^{1}$
}

\begin{abstract}
É com satisfação que apresentamos aos leitores este número especial dedicado à área de infância e adolescência, e mais especialmente ao percurso do trabalho desenvolvido pelo Espaço Lúdico Terapêutico do Laboratório de Estudos sobre Deficiência e Cotidiano do Curso de Terapia Ocupacional da USP, em seus 10 anos de atividades voltadas para o acompanhamento de crianças e adolescentes, o ensino e a pesquisa no campo da deficiência mental e distúrbios afetivos.

O questionamento e o confronto das formas tradicionais de relação com a deficiência, os processos de desinstitucionalização, a consciência sobre a necessidade de reconhecimento do direito à diferença, impulsionam e alimentam a invenção de novas instituições e práticas como as aqui relatadas.

O deslocamento do olhar da deficiência para a pessoa em seu contexto e de acordo com suas necessidades, complexifica as exigências do cuidar e trás para todos os sujeitos envolvidos a oportunidade de protagonizar a transformação da velha cultura reabilitativa, excludente e normativa por excelência.

Nas últimas décadas, a terapia ocupacional vem sendo desafiada a inovar, transformar e produzir novas respostas para as populações vulnerabilizadas pela deficiência e pelo estigma a ela atribuído. Podemos dizer que nesse percurso encontramos aquilo que hoje convencionamos chamar de "Boas Práticas" e que o nosso campo profissional tem sido alimentado pelo desenvolvimento de projetos e experiências que, embora ainda não hegemônicas, tem respondido concomitantemente aos desafios éticos e técnicos colocados pela construção do direito à saúde e a vida como princípio orientador das ações assistenciais.

Neste volume, o leitor poderá percorrer alguns caminhos práticos e teóricos que além de nos estimular a um fazer e a um pensar diferente, no campo específico das ações voltadas para crianças e adolescentes, propicia a reflexão mais ampla sobre a tendência atualmente desenvolvida pela terapia ocupacional que, inserida nos processos de desinstitucionalização, tem se orientado por um ideário comum que se caracteriza pela produção de projetos terapêuticos participativos e integrados na vida cotidiana das pessoas.
\end{abstract}

\footnotetext{
${ }^{(1)}$ Docentes do Curso de Gradução em Terapia Ocupacional da FMUSP.

Endereço para correspondência: Departamento de Fisioterapia, Fonoaudiologia e Terapia Ocupacional da Faculdade de Medicina da Universidade de São Paulo. Rua Cipotânea, 51. Cidade Universitáira - CEP: 05360-000 - São Paulo, SP.
} 